\title{
Retraction Note to: Relationships of $L D L R$ genetic polymorphisms with cerebral infarction: a meta-analysis
}

\author{
Hai-Cheng Yan ${ }^{1}$ - Wei Wang ${ }^{2}$ - Chang-Wu Dou ${ }^{3} \cdot$ \\ Fu-Ming $\operatorname{Tian}^{3} \cdot$ Song-Tao $\mathbf{Q i}^{1}$
}

Published online: 18 August 2015

(C) Springer Science+Business Media Dordrecht 2015

\section{Retraction Note to: Mol Biol Rep (2014) 41:4425-4434 \\ DOI 10.1007/s11033-014-3313-4}

The Publisher and Editor retract this article in accordance with the recommendations of the Committee on Publica tion Ethics (COPE). After a thorough investigation we have strong reason to believe that the peer review process was compromised.

The online version of the original article can be found under doi:10.1007/s11033-014-3313-4.

Song-Tao Qi

qisongtao121@163.com

1 Department of Neurosurgery, Nanfang Hospital, Southern Medical University, Avenue North Road No. 1838,

Guangzhou 510515, People's Republic of China

2 Department of Respiratory Medicine, Guangzhou Institute of Respiratory Diseases, Guangzhou 510120,

People's Republic of China

3 Department of Neurosurgery, Affiliated Hospital of Inner Mongolia Medical University, Hohhot 010050,

People's Republic of China 